\title{
Molecular Insight into the Anti-Inflammatory Effects of the Curcumin Ester Prodrug Curcumin Diglutaric Acid In Vitro and In Vivo
}

\author{
Rianthong Phumsuay ${ }^{1}$, Chawanphat Muangnoi ${ }^{2}$, Peththa Wadu Dasuni Wasana ${ }^{3}{ }^{\circ}$, \\ Hasriadi $^{3}\left(\mathbb{D}\right.$, Opa Vajragupta 4 (D), Pornchai Rojsitthisak ${ }^{5,6}$ (D) and Pasarapa Towiwat $6,7, *$ (D) \\ 1 Inter-Department Program of Pharmacology, Graduate School, Chulalongkorn University, Bangkok 10330, \\ Thailand; Rianthong.P@student.chula.ac.th \\ 2 Institute of Nutrition, Mahidol University, Salaya, Nakhon Pathom 73170, Thailand; \\ chawanphat.mua@mahidol.ac.th \\ 3 Pharmaceutical Sciences and Technology Program, Faculty of Pharmaceutical Sciences, Chulalongkorn \\ University, Bangkok 10330, Thailand; dasuniwasana@ahs.ruh.ac.lk (P.W.D.W.); adhiehasri@gmail.com (H.) \\ 4 Research Affairs, Faculty of Pharmaceutical Sciences, Chulalongkorn University, Bangkok 10330, Thailand; \\ opa.vaj@mahidol.ac.th \\ 5 Department of Food and Pharmaceutical Chemistry, Faculty of Pharmaceutical Sciences, Chulalongkorn \\ University, Bangkok 10330, Thailand; pornchai.r@chula.ac.th \\ 6 Natural Products for Ageing and Chronic Diseases Research Unit, Chulalongkorn University, \\ Bangkok 10330, Thailand \\ 7 Department of Pharmacology and Physiology, Faculty of Pharmaceutical Sciences, \\ Chulalongkorn University, Bangkok 10330, Thailand \\ * Correspondence: pasarapa.c@chula.ac.th; Tel.: +66-2-218-8326
}

Received: 13 July 2020; Accepted: 3 August 2020; Published: 9 August 2020

\begin{abstract}
Curcumin diglutaric acid (CurDG), an ester prodrug of curcumin, has the potential to be developed as an anti-inflammatory agent due to its improved solubility and stability. In this study, the anti-inflammatory effects of CurDG were evaluated. The effects of CurDG on inflammatory mediators were evaluated in LPS-stimulated RAW 264.7 macrophage cells. CurDG reduced the increased levels of NO, IL-6, and TNF- $\alpha$, as well as iNOS and COX-2 expression in cells to a greater extent than those of curcumin, along with the potent inhibition of MAPK (ERK1/2, JNK, and p38) activity. The anti-inflammatory effects were assessed in vivo by employing a carrageenan-induced mouse paw edema model. Oral administration of CurDG demonstrated significant anti-inflammatory effects in a dose-dependent manner in mice. The effects were significantly higher compared to those of curcumin at the corresponding doses $(p<0.05)$. Moreover, $25 \mathrm{mg} / \mathrm{kg}$ curcumin did not exert a significant anti-inflammatory effect for the overall time course as indicated by the area under the curve data, while the equimolar dose of CurDG produced significant anti-inflammatory effects comparable with 50, 100, and $200 \mathrm{mg} / \mathrm{kg}$ curcumin $(p<0.05)$. Similarly, CurDG significantly reduced the proinflammatory cytokine expression in paw edema tissues compared to curcumin $(p<0.05)$. These results provide the first experimental evidence for CurDG as a promising anti-inflammatory agent.
\end{abstract}

Keywords: curcumin; curcumin diglutaric acid; inflammation; carrageenan-induced paw edema

\section{Introduction}

Macrophage activation plays a primary role in host immune defense mechanisms, specifically in the inflammatory response. Inflammation is a key response of the body that defends the body's tissues against endogenous and exogenous stimuli, such as tissue damage, pathogens, and chemical irritants. The cardinal signs of inflammation include redness, heat, swelling, and pain, which lead 
to compromised functionality of tissues and organs [1]. The inflammation process is associated with the activation of nuclear factor kappa $\mathrm{B}(\mathrm{NF}-\mathrm{KB})$ and phosphorylation of mitogen-activated protein kinases (MAPKs), namely p-38, c-Jun N-terminal kinases (JNKs), and extracellular-signal-regulated kinases (ERK1/2), resulting in the production and release of proinflammatory cytokines, including interleukin-1 beta (IL-1 $\beta$ ), interleukin-6 (IL-6), and tumor necrosis factor alpha (TNF- $\alpha$ ); and increased levels of inflammatory mediators, namely nitric oxide (NO) and prostaglandin E2 (PGE2), which are generated by inducible nitric oxide synthase (iNOS) and cyclooxygenase-2 (COX-2), respectively [2]. Even though inflammation is considered as a physiological response to defend the host against both external and internal stimuli, it also contributes to the pathophysiology of various chronic diseases, including rheumatoid arthritis, autoimmune disorders, atherosclerosis, and cancer [3] when these protective responses dysregulate. Therefore, the downregulation of the inflammatory response would be a surrogate approach for the treatment and prevention of pathological complications associated with chronic inflammatory diseases. Even though non-steroidal anti-inflammatory drugs (NSAIDs) are used in the management of acute inflammation, their undesirable effects have led to the search for new compounds from plants to be used in the prevention and treatment of inflammatory disorders with improved safety profiles.

Curcumin (Figure 1A) is a major bioactive phytochemical contained in the rhizome of turmeric (Curcuma longa L.), which has several pharmacological activities, including antioxidant, anti-inflammatory, anticancer, and anti-infective properties [4]. Based on previous research, in vitro studies that indicate curcumin inhibits the production of NO, TNF- $\alpha$, and IL- $1 \beta$ and suppresses NF- $\mathrm{KB}$ activation, which regulates the expression of genes in the inflammatory process [5]. In addition, curcumin downregulated the activity of COX-2 and iNOS enzymes related to inflammation. Many studies have investigated the anti-inflammatory effects of curcumin in animal models. One study reported that oral administration of curcumin inhibited edema induced by carrageenan at doses of $50-200 \mathrm{mg} / \mathrm{kg}$ in mice [6]. Moreover, curcumin has demonstrated beneficial effects in various diseases associated with inflammation, such as diabetes mellitus [7], myocardial infarction [8], and migraine [9]. While curcumin has many advantageous pharmacological properties, its development as a therapeutic agent is limited on account of its low aqueous solubility, poor absorption, and metabolic instability, which lead to poor oral bioavailability.

(A)<smiles>COc1cc(/C=C/C(=O)/C=C/c2ccc(O)c(OC)c2)ccc1O</smiles>

(B)

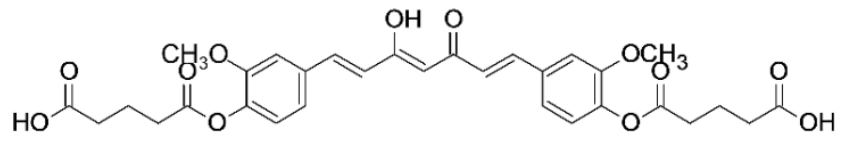

Figure 1. Chemical structures of (A) curcumin and (B) curcumin diglutaric acid (CurDG).

The prodrug approach has been applied to overcome the poor physicochemical and biopharmaceutical properties of numerous phytochemicals. Previously, we synthesized a glutaric ester prodrug of curcumin, the so-called curcumin diglutaric acid (CurDG) (Figure 1B), to improve the solubility of curcumin. We found that CurDG and curcumin were soluble in water at about 7.48 and $0.07 \mu \mathrm{g} / \mathrm{mL}$, respectively, indicating about 100 times higher water solubility of CurDG compared to that of curcumin. In biological buffers at body temperature, curcumin and CurDG are sparingly soluble $(<0.025 \mu \mathrm{g} / \mathrm{mL})$, both in $0.1 \mathrm{M} \mathrm{HCl}$ and acetate buffer $\mathrm{pH} 4.5$. The solubility of CurDG in phosphate buffer ( $\mathrm{pH}$ 6.8) is greater than that of curcumin, at $1.43 \mu \mathrm{g} / \mathrm{mL}$ and $0.025 \mu \mathrm{g} / \mathrm{mL}$, respectively. For the stability study, the hydrolysis rate $\left(\mathrm{K}_{o b s}\right)$ of CurDG at physiological pH 7.4 was found to be $2.62 \mathrm{~h}^{-1}$, which is higher the $\mathrm{pH}$ values of 1.2 and $\mathrm{pH} 4.5$ ( $\mathrm{K}_{o b s} 0.048$ and 0.033 , respectively). This indicates the possibility of CurDG to extend the degradation time of the released curcumin, facilitating the gradual 
absorption of CurDG through the cell membrane before the fast release of curcumin in plasma. The $\mathrm{K}_{o b s}$ and half-life for CurDG hydrolysis in human plasma were $5.83 \mathrm{~h}^{-1}$ and $0.12 \mathrm{~h}$, respectively, while the CurDG prodrug was totally converted to curcumin in human plasma within $2 \mathrm{~h}$ [10]. Therefore, CurDG may have the potential to be developed for clinical applications, especially in the development of anti-inflammatory agents. However, the anti-inflammatory effect of CurDG has not been well reported. Hence, the aim of this study is to investigate the effects of CurDG on the proinflammatory cytokines in lipopolysaccharide (LPS)-stimulated RAW 264.7 cells, along with its anti-inflammatory activity in a carrageenan-induced mouse paw edema model, to provide evidence that this prodrug has better anti-inflammatory potential than curcumin.

\section{Results}

\subsection{Cytotoxic Effects on Cell Viability of RAW 264.7 Cells}

The cytotoxic effects of curcumin and CurDG on the viability of RAW 264.7 were evaluated using MTT assay. The results are presented as a percentage of cell viability. The results demonstrated that concentrations of up to $5 \mu \mathrm{M}$ for both compounds had no cytotoxic effect on cell viability in RAW 264.7 cells (Figure 2). Therefore, we used the highest concentrations of curcumin and CurDG at $5 \mu \mathrm{M}$ for subsequent experiments to ensure effective and sustained compound activity over the treatment period.

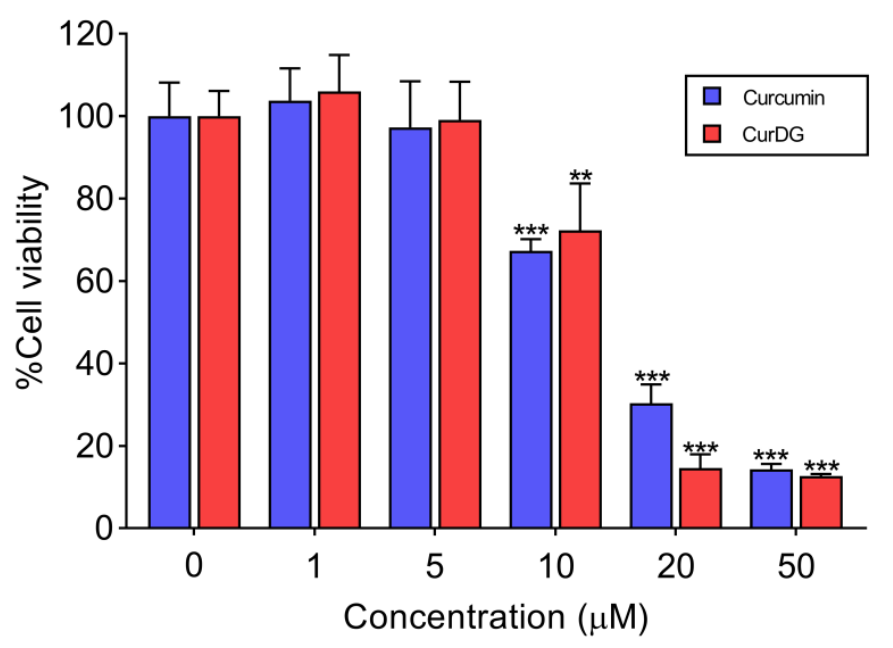

Figure 2. Effects of curcumin and CurDG on the cell viability of RAW 264.7 macrophage cells. Cells were treated with curcumin or CurDG at 1-50 $\mu \mathrm{M}$ and incubated for $24 \mathrm{~h}$. Data show the mean \pm SD values of three independent experiments. Note: ${ }^{* *} p<0.01$ and ${ }^{* * *} p<0.001$ compared with the control group.

\subsection{Effects on NO Levels in LPS-Stimulated RAW 264.7 Cells}

To investigate the effects of curcumin and CurDG on the inhibition of LPS-stimulated NO production in RAW 264.7 cells, the quantifier of NO production was determined by comparing its absorbance with the standard curve of nitrite $\left(\mathrm{NO}_{2}{ }^{-}\right)$. The results showed that the LPS-treated RAW 264.7 cells significantly increased the nitrite levels, peaking at $43.14 \pm 0.81 \mu \mathrm{M}$, compared with the control group $(0.07 \pm 0.04)$. Pre-treatment of cells with both curcumin and CurDG at $5 \mu \mathrm{M}$ for $1 \mathrm{~h}$ significantly decreased the levels of nitrite by $30 \%(30.33 \pm 3.34 \mu \mathrm{M})$ and $60 \%(17.29 \pm 2.90 \mu \mathrm{M})$, respectively, when compared to the LPS control group (Figure 3B). Additionally, treatment with only curcumin and CurDG did not affect the production of NO in RAW 264.7 cells (Figure 3B). The cytotoxic effects of curcumin and CurDG co-treated with LPS were measured using the MTT assay. The results showed that treatment with curcumin or CurDG with LPS had no cytotoxicity on RAW 264.7 cells, suggesting that the decrease in NO production from LPS-stimulated RAW 264.7 cells was 
not caused by the decrease in the cell population (Figure 3A). These results indicated that the CurDG had an anti-inflammatory effect on LPS-stimulated RAW 264.7 cells by decreasing NO production in LPS-stimulated RAW 264.7 cells at significantly higher levels than that of curcumin.

(A)

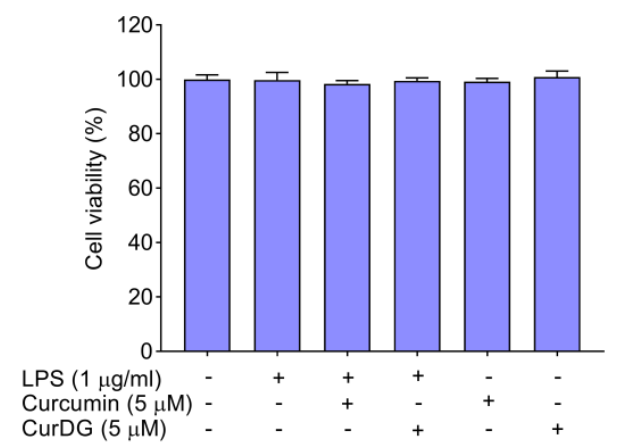

(C)

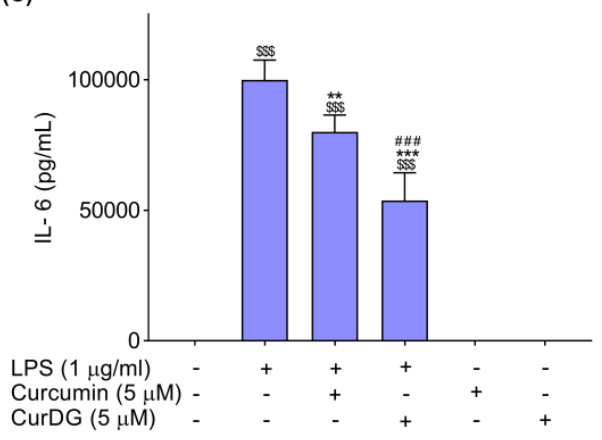

(E)

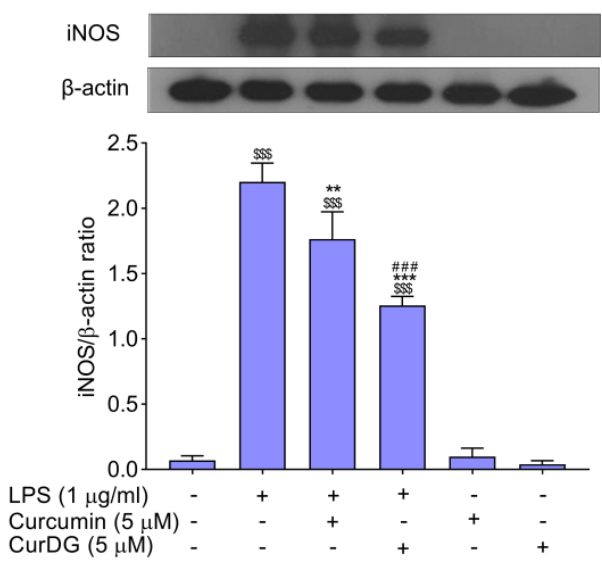

(B)

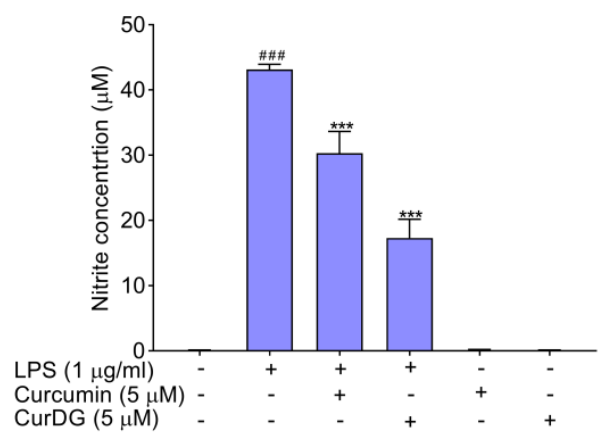

(D)

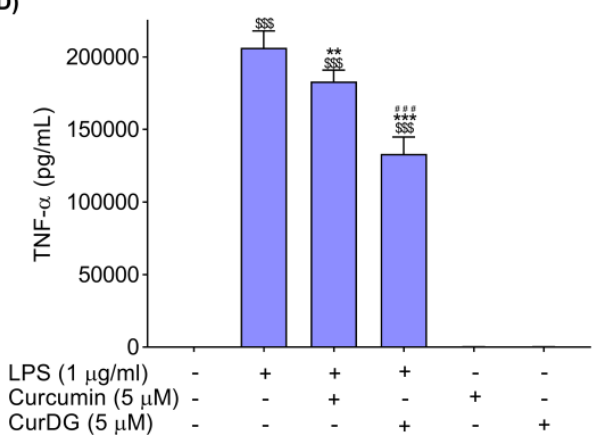

(F)
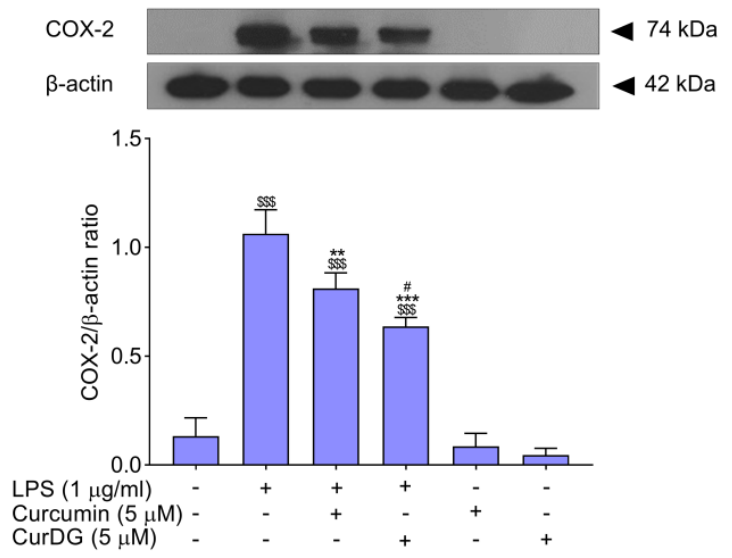

Figure 3. Effects of curcumin and CurDG on cell viability (A), NO production (B), and proinflammatory cytokine and mediator expression in LPS-stimulated RAW 264.7 cells. Cells were pre-treated with $5 \mu \mathrm{M}$ curcumin or CurDG for $1 \mathrm{~h}$, followed by the addition of $1 \mu \mathrm{g} / \mathrm{mL}$ LPS for $24 \mathrm{~h}$. The culture medium was collected for NO determination and the cells were determined for cell viability with MTT assays. The IL-6 (C) and TNF- $\alpha$ (D) levels measured by ELISA assay are presented in pg/mL. The expression of iNOS (E) and COX-2 (F) proteins were determined by Western blot analysis, and these graphs were analyzed using the ImageJ software. The values of iNOS and COX-2 proteins were normalized with $\beta$-actin. The data present the mean $\pm \mathrm{SD}, n=3$ of three independent experiments. Note: $\$ \$ \$<<0.001$ compared to the control group and ${ }^{* *} p<0.01 ;{ }^{* *} p<0.001$ compared to the LPS control group and \# $p<0.05 ;{ }^{\# \#} p<0.001$ significant difference between curcumin- and CurDG-treated groups. 


\subsection{Effect on IL-6 and TNF- $\alpha$ Levels in LPS-Stimulated RAW 264.7 Cells}

The effects of curcumin and CurDG on the levels of the proinflammatory cytokines (IL-6 and TNF- $\alpha$ ) in LPS-stimulated RAW 264.7 cells were measured using ELISA. The result demonstrated that cells treated with LPS showed significantly increased production of IL- 6 and TNF- $\alpha$ of up to $99,833 \pm 7610$ and $206,332 \pm 11,623 \mathrm{pg} / \mathrm{mL}$, respectively, compared to the control group $(75 \pm 1.8$ and $83 \pm 75, \mathrm{pg} / \mathrm{mL}$ respectively) (Figure 3C,D). Pre-treatment of cells with curcumin at $5 \mu \mathrm{M}$ for $1 \mathrm{~h}$ significantly decreased the levels of IL- 6 and TNF- $\alpha$ by $20 \%(79,917 \pm 6487 \mathrm{pg} / \mathrm{mL})$ and $11 \%$ $(18,3016 \pm 7922 \mathrm{pg} / \mathrm{mL})$, respectively, when compared to the LPS-stimulated group (Figure 3C,D); while pre-treatment of cells with CurDG at $5 \mu \mathrm{M}$ for $1 \mathrm{~h}$ significantly attenuated the increased levels of IL-6 and TNF- $\alpha$ by $46 \%(53,708 \pm 10,567 \mathrm{pg} / \mathrm{mL})$ and $35 \%(133,207 \pm 11,653 \mathrm{pg} / \mathrm{mL})$, respectively, when compared to the LPS-stimulated group. Additionally, treatment with only curcumin and CurDG did not affect the production of IL-6 and TNF- $\alpha$ in RAW 264.7 cells (Figure 3C,D). These results indicate that CurDG decreases the IL-6 and TNF- $\alpha$ secretion from LPS-stimulated RAW 264.7 cells to a greater extent than curcumin.

\subsection{Effects on iNOS and COX-2 Expression in LPS-Stimulated RAW 264.7 Cells}

To determine the effects of curcumin and CurDG on expression levels of iNOS and COX-2 in LPS-stimulated RAW 264.7 cells, these protein expressions were detected using Western immunoblotting. As shown in Figure 3E,F, protein expression of iNOS and COX-2 was significantly increased by approximately 32- and 8-fold, respectively, in RAW 264.7 cells stimulated with LPS. Pre-treatment of cells with curcumin at $5 \mu \mathrm{M}$ for $1 \mathrm{~h}$ significantly decreased the expression of iNOS and COX-2 by $20 \%$ and $24 \%$, respectively, when compared to the LPS-treated group (Figure 3E,F), whereas pre-treatment of cells with CurDG at $5 \mu \mathrm{M}$ for $1 \mathrm{~h}$ significantly decreased the expression of iNOS and COX-2 by $43 \%$ and $40 \%$, respectively, when compared to the LPS-induced group (Figure 3E,F). In addition, treatment with only curcumin and CurDG did not affect the expression of iNOS and COX-2 in control macrophage cells (Figure 3E,F). These results indicate that CurDG decreases the expression of iNOS and COX-2 from LPS-stimulated RAW 264.7 cells to a greater extent than curcumin.

\subsection{Effectz on iNOS and COX-2 Expression in LPS-Stimulated RAW 264.7 Cells}

The effects of curcumin and CurDG on intracellular signaling pathway protein MAPK expression, including ERK1/2, JNK, and p38, in LPS-stimulated RAW 264.7 cells were investigated using Western blot analysis. The LPS treatment significantly increased the expression of p-ERK, p-JNK, and p-p38 by approximately 1.5-, 2.1-, and 18.9-fold, respectively, in comparison with the control group (Figure 4A-C). Pre-treatment of cells with curcumin at $5 \mu \mathrm{M}$ for $1 \mathrm{~h}$ significantly decreased the expression of p-ERK, p-JNK, and p-p38 by $24 \%, 21 \%$. and $28 \%$, respectively, when compared to the LPS-stimulated group (Figure 4); while pre-treatment of cells with CurDG at $5 \mu \mathrm{M}$ for $1 \mathrm{~h}$ significantly decreased the expression of p-ERK, p-JNK, and p-p38 by $42 \%, 46 \%$, and $62 \%$, respectively, when compared to the LPS-stimulated group (Figure 4). Additionally, the treatment with only curcumin and CurDG did not affect the expression of p-ERK, p-JNK, or p-p38 in control cells (Figure 4). The results indicate that CurDG decreases the expression of p-ERK, p-JNK, and p-p38 from LPS-stimulated RAW 264.7 cells to a greater extent than curcumin. 


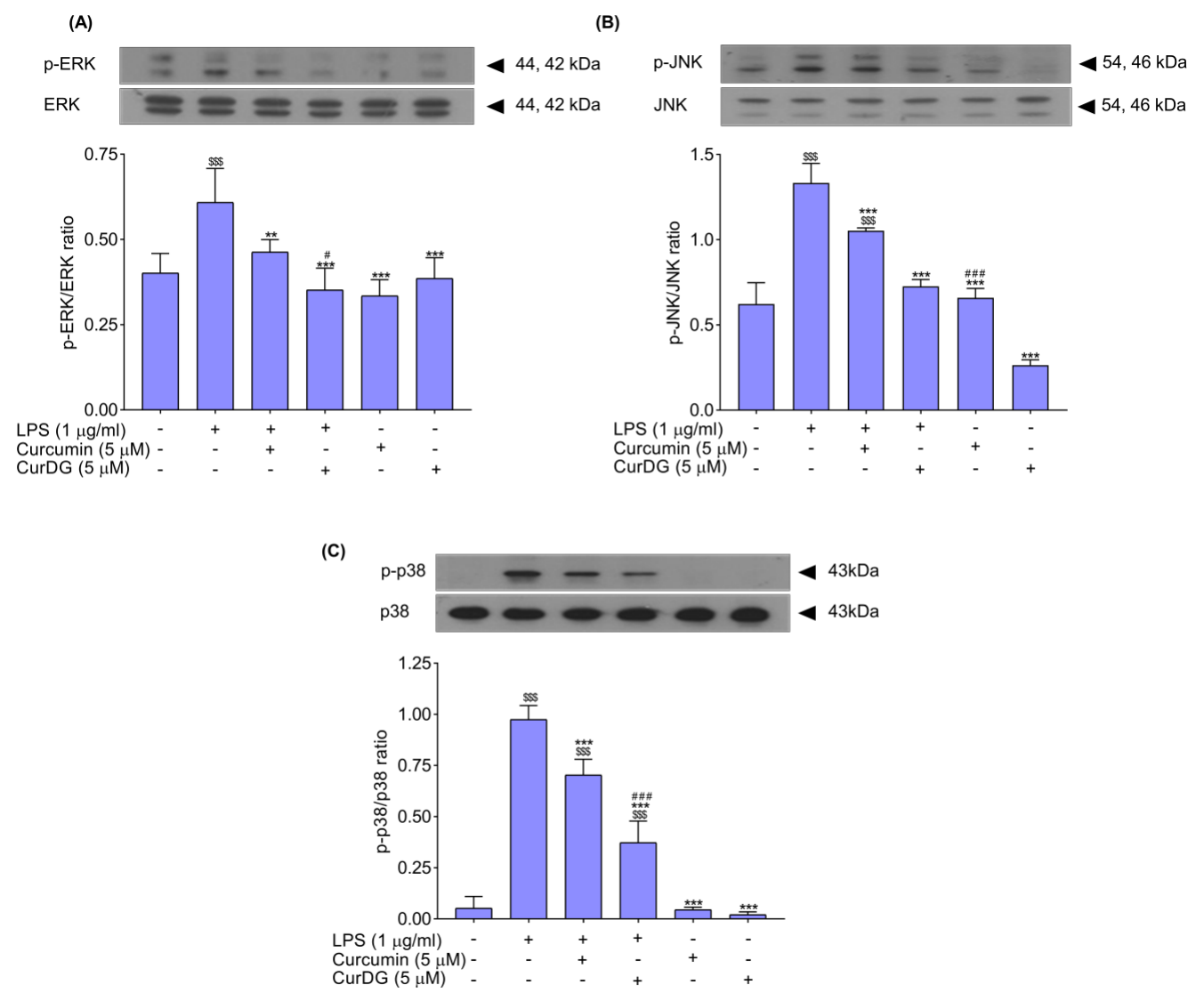

Figure 4. Effects of curcumin and CurDG on the expression of p-ERK (A), p-JNK (B), and p-p38 (C) in LPS-stimulated RAW 264.7 cells. Cells were co-treated with curcumin and LPS or CurDG and LPS for $24 \mathrm{~h}$. The protein levels of phosphorylated and total forms of MAPKs were determined by Western blot analysis. The graphs were analyzed using the ImageJ software, and data show the mean \pm SD of three independent tests. Phosphorylation levels of ERK1/2, JNK, and p38 were normalized with total levels of ERK1/2, JNK, and p38 densitometric values, respectively. Note: $\$ \$ p<0.001$ compared to the control group; ${ }^{* *} p<0.01$ and ${ }^{* * *} p<0.001$ compared to the LPS-stimulated group; ${ }^{*} p<0.05$ and ${ }^{\# \# \#} p<0.001$, significant differences between curcumin- and CurDG-treated groups.

\subsection{Inhibitory Effects of CurDG on Carrageenan-Induced Mouse Hind Paw Edema}

The anti-inflammatory activities of curcumin and CurDG on the paw edema induced by carrageenan are shown in Figure 5. The morphological characteristics of mice paws observed at $6 \mathrm{~h}$ after carrageenan injection are shown in Figure 5A. Mice who received carrageenan in their left hind paws showed progressive increases in the volume of edema compared to the paw volume before injection (Figure 5A(a,b)). The morphologies of indomethacin-, curcumin-, and CurDG-treated paws showed reduced swelling, while swelling in the curcumin group remained higher compared to that of indomethacin- and CurDG-treated groups. As shown in Figure 5B, the subcutaneous administration of carrageenan produced a time-dependent increase in paw edema, which reached a maximum at $3 \mathrm{~h}(74.9 \pm 9.0 \%$ increase in paw volume $)$ and was maintained thereafter for $6 \mathrm{~h}$, indicating acute inflammation. Oral administration of curcumin at doses of 25,50,100, and $200 \mathrm{mg} / \mathrm{kg}$ and equimolar doses of CurDG significantly reduced the development of the carrageenan-induced paw edema compared to that of the vehicle-treated group $(p<0.05)$ at $1-6 \mathrm{~h}$ (Figure $5 \mathrm{~B})$. The orally administered $25 \mathrm{mg} / \mathrm{kg}$ curcumin significantly reduced paw edema compared to the vehicle-treated group after only $3 \mathrm{~h}$ of induction (Figure 5B,C), with a maximal $32.3 \pm 5.6 \%$ inhibition of paw edema at $6 \mathrm{~h}$. However, CurDG at a dose equimolar to $25 \mathrm{mg} / \mathrm{kg}$ curcumin produced a greater reduction in paw edema, even after $1 \mathrm{~h}$ of carrageenan induction一the maximum effect $(69.8 \pm 4.3 \%$ inhibition of paw edema) was observed at $6 \mathrm{~h}$ (Figure 5B,C). 
A. Macroscopic photographs of the mice hind paw

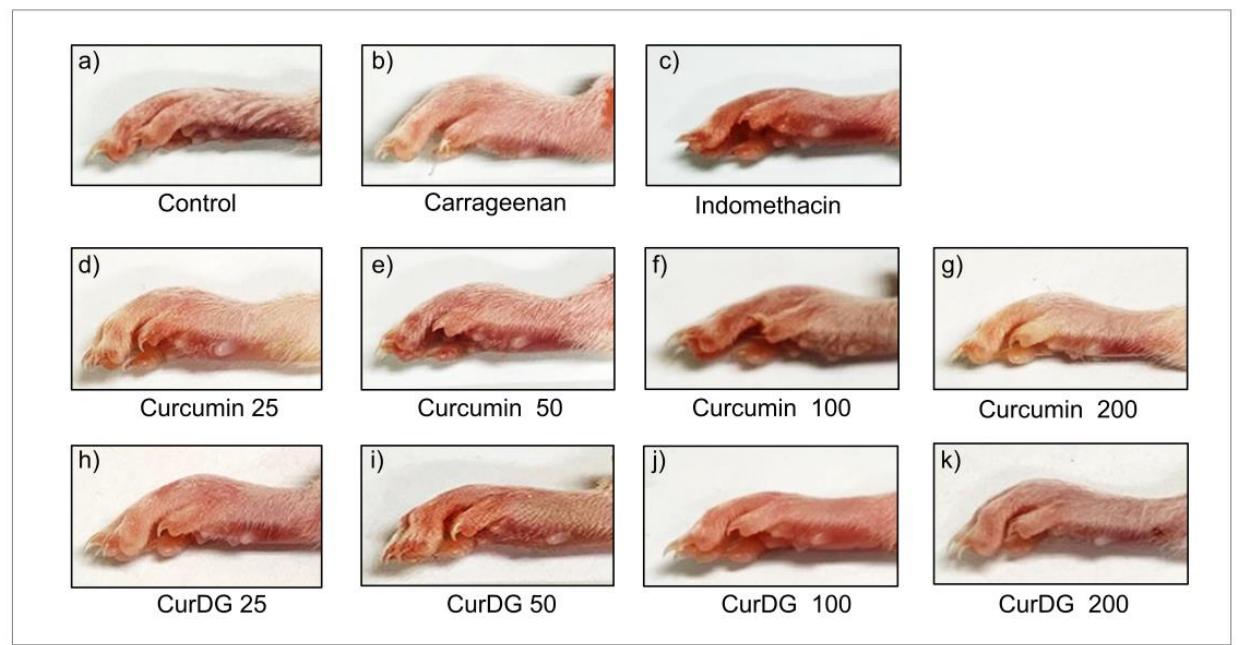

B. \% increase in paw volume with the treatments in carrageenan-induced paw edema in mice

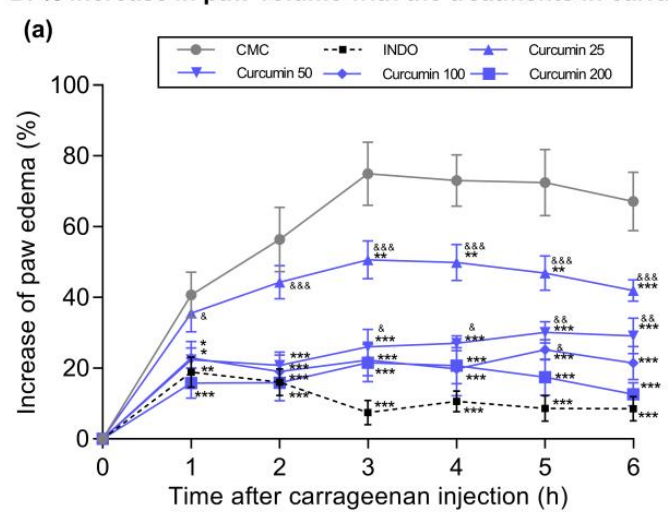

C. $\%$ Increase in paw edema with the treatment of 25 $\mathrm{mg} / \mathrm{kg}$ curcumin and its equimolar dose of CurDG

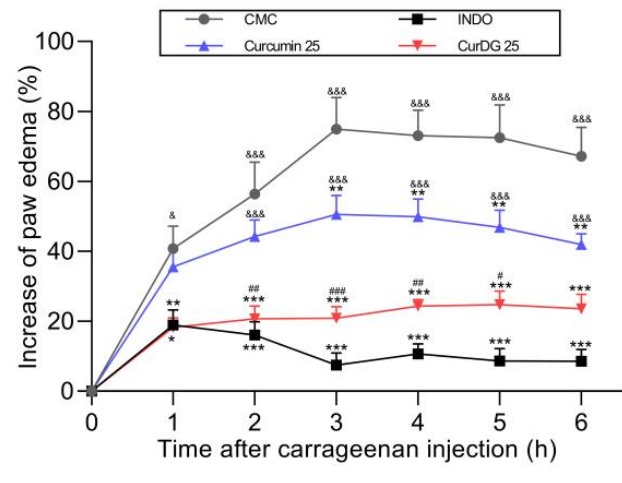

(b)

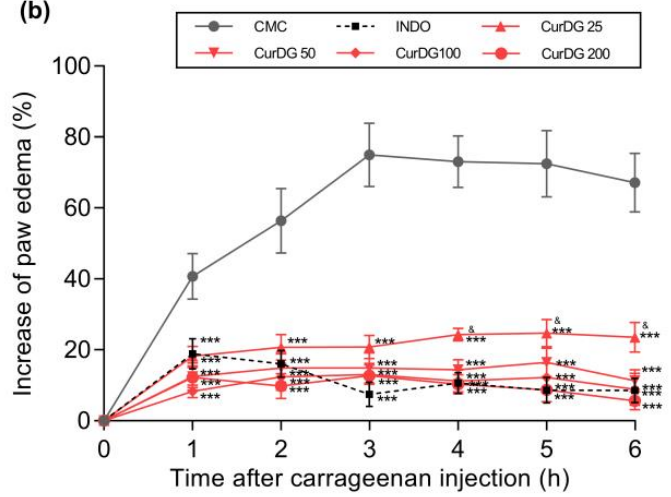

D. Area under the curve (AUC) for the \%increase in paw edema volume over $6 \mathrm{~h}$ with different treatments

a Curcumin $\square$ CurDG (equimolar with curcumin)

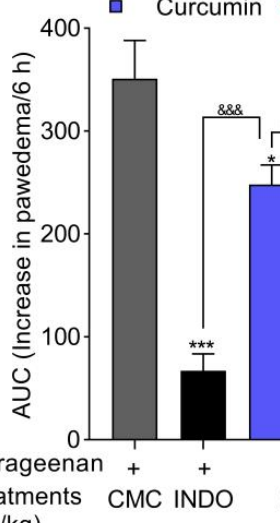

$(\mathrm{mg} / \mathrm{kg})$

Figure 5. Anti-inflammatory effects of curcumin and CurDG on carrageenan-induced hind paw edema. (A) Morphological features of the left hind paw of each mice $6 \mathrm{~h}$ after carrageenan administration. (B) The percentage increase of paw edema after carrageenan injection following oral administration of $0.5 \% \mathrm{CMC}$, indomethacin (10 mg/kg), and curcumin (a) and CurDG (b) at doses of 25, 50, 100, and $200 \mathrm{mg} / \mathrm{kg}$ ). (C) Effect of CurDG 25 on the \% increase of paw edema compared to its respective controls. (D) The area under the paw edema effect-time curve (AUC 0-6 h). The data are the mean \pm SEM for 8 mice. The results were analyzed using an ANOVA and Fisher's LSD post hoc test. Note: ${ }^{*} p<0.05,{ }^{* *} p<0.01$, and ${ }^{* * *} p<0.001$ compared to the vehicle-treated control; ${ }^{*} p<0.05$, \#\# $p<0.01$ and ${ }^{\# \#} p<0.001$, significant differences between curcumin- and CurDG-treated groups; $\& p<0.05, \& \& p<0.01$, and \&\&\& $p<0.001$, statistical differences in the treatment groups compared with indomethacin-treated group (INDO). 
For a clear comparison between compounds, the analysis of the edematous effect was plotted along a time curve and converted into the area under the curve (AUC) (Figure 5C). The anti-inflammatory effects of both curcumin and CurDG increased in a dose-dependent manner, with the highest dose of curcumin and its equimolar dose of CurDG having equal efficacy $(p>0.05)$. In contrast, the anti-inflammatory efficacy of CurDG at doses equimolar to 25,50 , and $100 \mathrm{mg} / \mathrm{kg}$ curcumin was significantly higher compared to that of curcumin $(p<0.05)$. Furthermore, the anti-inflammatory efficacy of all doses of CurDG, as well as curcumin except $25 \mathrm{mg} / \mathrm{kg}$, was comparable with that of the reference drug indomethacin $(10 \mathrm{mg} / \mathrm{kg}$, orally). More specifically, CurDG at the lowest dose tested produced a significant anti-inflammatory effect, whereas curcumin did not produce a significant anti-inflammatory effect at the same dose level $(25 \mathrm{mg} / \mathrm{kg})$. The anti-inflammatory effect of CurDG 25 was comparable with that of curcumin at the dose levels of 50,100, and $200 \mathrm{mg} / \mathrm{kg}$. These results show that CurDG more effectively reduced paw edema in a dose-dependent manner compared to that of curcumin in mice with carrageenan-induced inflammation.

\subsection{CurDG-Mediated Inhibition of Proinflammatory Cytokine Expression in Mouse Paw Edema Model}

The molecular insight into the anti-inflammatory effects of CurDG was further investigated by analyzing the TNF- $\alpha$ and IL- 6 levels-the proinflammatory cytokines of the inflamed paw. As shown in Figure 6, the injection of carrageenan significantly elevated the expression of both IL-6 $(8239 \pm 1361 \mathrm{pg} / \mathrm{mL})$ and TNF- $\alpha(69.0 \pm 5.9 \mathrm{pg} / \mathrm{mL})$ (Figure 6A,B) in the inflamed paw compared to the control paw $(243.7 \pm 116.1$ and $31.9 \pm 0.4 \mathrm{pg} / \mathrm{mL}$ for IL- 6 and TNF- $\alpha$, respectively) $(p<0.001)$. The mice were administered orally with all four doses of CurDG equimolar to 25, 50, 100, and $200 \mathrm{mg} / \mathrm{kg}$ curcumin and showed significant reductions in carrageenan-induced proinflammatory cytokine release in paw tissues $(p<0.05)$ compared to the vehicle-treated group. The effect was comparable with indomethacin $10 \mathrm{mg} / \mathrm{kg}$ at the doses of 100 and $200 \mathrm{mg} / \mathrm{kg}$ for IL-6 expression and at all doses for TNF- $\alpha$ expression. Similarly, curcumin also significantly downregulated the expression of carrageenan-induced proinflammatory cytokines at doses of 50,100, and $200 \mathrm{mg} / \mathrm{kg}$. In agreement with the results of paw edema, curcumin $25 \mathrm{mg} / \mathrm{kg}$ did not significantly reduce the expression of either IL-6 $(8211 \pm 1111 \mathrm{pg} / \mathrm{mL})$ or TNF- $\alpha(68.3 \pm 2.5 \mathrm{pg} / \mathrm{mL})$ in paw tissues compared to the vehicle control group. Interestingly, the inhibitory effect of CurDG at the dose equimolar to $25 \mathrm{mg} / \mathrm{kg}$ curcumin was significantly higher $(2640 \pm 804.6$ and $52.6 \pm 2.0 \mathrm{pg} / \mathrm{mL}$, respectively, for IL-6 and TNF- $\alpha)$ than that of the parent compound, curcumin $(p<0.05)$. Above this, the inhibitory effects of CurDG at a dose equimolar to $25 \mathrm{mg} / \mathrm{kg}$ curcumin was comparable with those of curcmin at 50,100, and $200 \mathrm{mg} / \mathrm{kg}$ dose levels. With respect to the reference drug, indomethacin, CurDG at all doses tested resulted in comparable $(p>0.05)$ reductions in TNF- $\alpha$ levels in paw tissues, except for the significantly lower inhibition of the IL-6 levels $(p<0.05)$ observed with CurDG doses equimolar to 25 and $50 \mathrm{mg} / \mathrm{kg}$ curcumin. Altogether, CurDG caused dominant inhibition in IL-6 levels compared to TNF- $\alpha$ levels in the carrageenan-induced paw tissues. 


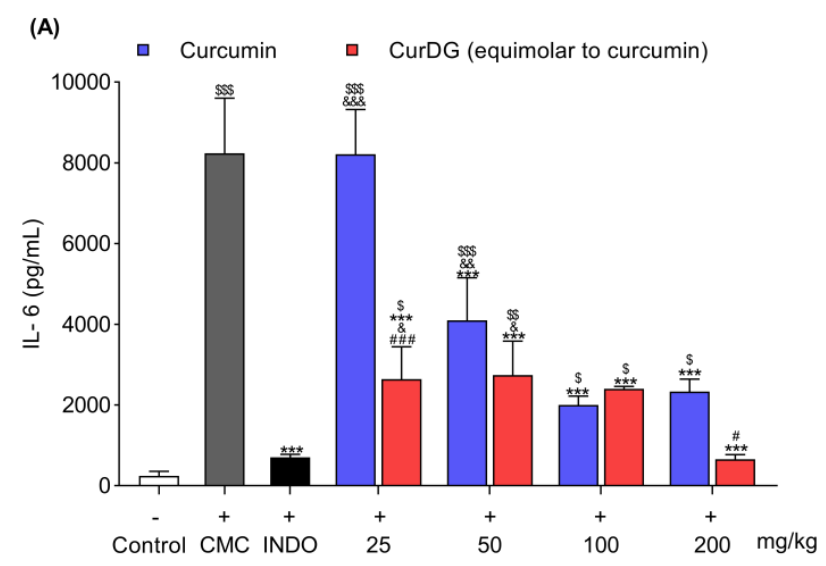

(B)

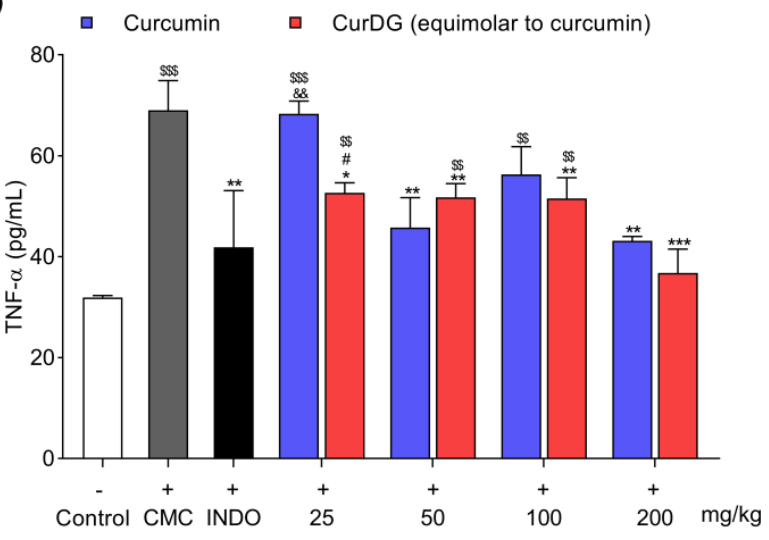

Figure 6. Effects of curcumin and CurDG on IL-6 (A) and TNF- $\alpha(\mathbf{B})$ levels in edema paw tissue. Results are shown as means \pm SEM ( $=8 /$ group). Note: $\$ p<0.05, \$ \$ p<0.01$ and $\$ \$ p<0.001$ compared to the naïve group; ${ }^{*} p<0.05,{ }^{* *} p<0.01$, and ${ }^{* * *} p<0.001$ compared to the carrageenan group; ${ }^{\#} p<0.05$ and ${ }^{\# \#} p<0.001$ indicate significant differences between curcumin- and CurDG-treated groups; ${ }^{\&} p<0.05$ and ${ }^{\& \&} p<0.01$ indicate statistical differences in the treatment groups compared with the indomethacin-treated group (INDO).

\section{Discussion}

The current study provides evidence of the improved anti-inflammatory effect of curcumin by its ester prodrug CurDG in both in vitro and in vivo models. CurDG in LPS-stimulated RAW 246.7 macrophage cells suppressed the levels of proinflammatory cytokines IL- 6 and TNF- $\alpha$; and the expression of proinflammatory mediators $\mathrm{NO}, \mathrm{COX}-2$, and iNOS via modulating MAPK pathways (ERK1/2, JNK, and p38) to a greater extent than curcumin. In line with the in vitro study, CurDG also exhibited higher anti-inflammatory effects in carrageenan-induced paw edema mice, where it significantly reduced the expression of proinflammatory cytokines (TNF- $\alpha$ and IL-6) in paw edema tissues compared to that of curcumin.

A prodrug is an inactive form of the parental drug that undertakes biotransformation to an active form when administered to the body and is intended to increase the performance of the parent drug. This approach is utilized to improve the properties of the parent drug, such as its physicochemical and pharmacokinetic properties [11]. Recently, several prodrugs with excellent anti-inflammatory enhancement and better safety profiles compared to their parent drugs have been reported, including sulindac, parecoxib, nabumetone, and nepafenac, all of which are commercially available on the market [12].

Studies including clinical trials have demonstrated the effectiveness of natural products on decreasing proinflammatory responses in many diseases $[13,14]$. Owing to poor physicochemical and pharmacokinetic properties, there has been much attention paid to developing prodrugs from natural products with better bioavailability and stability profiles than their parent compound, such as 
resveratrol prodrugs [15], quercetin-amino acid conjugates (quercetin prodrugs) [16], scutellarin prodrugs [17], and curcumin prodrugs [10,18]. The curcumin prodrug CurDG has shown increased water solubility and an increased antinociceptive effect [10]. Here, the anti-inflammatory effect of CurDG was evaluated in vivo using carrageenan-induced edema and its underlying molecular mechanisms in both LPS-stimulated RAW 264.7 cells and inflamed mice paw tissues. Hence, this is the first study to compare the anti-inflammatory effects of CurDG with those of its parent compound, curcumin.

Inflammation is an essential response from the body that protects the tissues from both endogenous and exogenous stimuli. The activation of macrophages plays a crucial function in host immune defense mechanisms, specifically in inflammatory pathways. Macrophages, which are activated by pathogens and chemicals including LPS, bind with Toll-like receptors (TLR-4) present in macrophages, which in turn activate several downstream signaling pathways, including signal transduction pathway kinases [19], which eventually activate transcription factor NF- $\mathrm{KB}$. This activation facilitates the translocation of NF-KB into the nucleus, where it binds with its response element, which then activates the expression of genes of several proinflammatory mediators [20]. During the state of chronic inflammation, these proinflammatory mediators are produced abundantly, initiating pathogenesis of the onset of numerous inflammatory disorders [21]. Moreover, LPS-stimulated macrophages lead to the phosphorylation of MAPK signaling proteins, including ERK1/2, JNK, and p38, which result in excessive secretion and expression of inflammatory mediators and proteins, including NO, TNF- $\alpha$, and IL-6, as well as the expression of iNOS and COX-2. Together these mediators play an important role in the induction of inflammation [22]. The results of the present study also demonstrated that LPS exposure activated the secretion of NO, TNF- $\alpha$, and IL-6, as well as the expression of iNOS and COX-2 in RAW 264.7 macrophage cells mediated via the phosphorylation of ERK1/2, JNK, and p38. Pre-treatment of cells with CurDG significantly inhibited all of these inflammatory cytokines and mediators compared to the parent drug, curcumin, indicating an improved anti-inflammatory effect of CurDG compared to curcumin.

As CurDG was able to inhibit LPS-stimulated inflammatory reactions in RAW 264.7 macrophage cells as compared to curcumin, the effect was also investigated using an in vivo approach. The carrageenan-induced paw edema is a commonly used in vivo model for screening of anti-inflammatory agents [23]. Development of paw edema induced by carrageenan is described as a biphasic event; the early phase ( $2 \mathrm{~h}$ post carrageenan injection) is mediated by the secretion of inflammatory mediators (histamine and serotonin), which is correlated with enhanced vascular permeability. The second phase (3-4 h post carrageenan injection) principally involves neutrophil infiltration into the site of inflammation and the release of PGE2 and cytokines [24]. Following the injection of carrageenan, the anti-inflammatory reaction is normally evaluated for $6 \mathrm{~h}$ [25]. In agreement with previous studies [26], our study results demonstrated a polynomial increase in the edema size with the administration of carrageenan, where the size of edema reached a maximum after three hours of carrageenan injection. Furthermore, the anti-inflammatory effect of orally administered curcumin in carrageenan-induced paw edema has been evaluated previously, demonstrating its significant anti-inflammatory effects at doses of $25-400 \mathrm{mg} / \mathrm{kg}$ compared to the vehicle treatment $[4,27]$. Similarly, in the present study, oral administration of curcumin at 25,50, 100, and $200 \mathrm{mg} / \mathrm{kg}$ effectively attenuated the carrageenan-induced paw edema in mice. Additionally, equimolar doses of CurDG produced significantly improved anti-inflammatory effects compared to curcumin at doses of 25,50 , and $100 \mathrm{mg} / \mathrm{kg}$. Moreover, the antiedematous effect of CurDG at the dose equimolar to $25 \mathrm{mg} / \mathrm{kg}$ curcumin was comparable with that of the reference drug, indomethacin (10 mg/kg, p.o.), a well-recognized non-steroidal anti-inflammatory drug (NSAID)and cyclooxygenase (COX-1 and 2) inhibitor, as well as curcumin at 50,100, and $200 \mathrm{mg} / \mathrm{kg}$. Curcumin at the same dose showed significantly lesser efficacy compared to indomethacin, indicating the improved therapeutic efficacy of curcumin by formulating its prodrug CurDG.

As per previous research findings, some of the synthesized curcumin-amino acid conjugate prodrugs also exhibited comparable anti-inflammatory activities to $10 \mathrm{mg} / \mathrm{kg}$ indomethacin (dose 
equimolar to $10.3 \mathrm{mg} / \mathrm{kg}$ curcumin) when administered to rats with carrageenan-induced paw edema [28]. However, in the previous study, the intraperitoneal route of administration was used. In line with that study, in our study the lowest dose of CurDG tested (dose mol equivalent to $25 \mathrm{mg} / \mathrm{kg}$ curcumin) showed comparable anti-inflammatory effects to indomethacin $10 \mathrm{mg} / \mathrm{kg}$ when administered orally. Moreover, CurDG $25 \mathrm{mg} / \mathrm{kg}$ showed more than $50 \%$ inhibition of paw edema at each time point tested. Hence, further studies are required using lower doses to gain a better understanding of the potency of CurDG relative to curcumin and to determine the dose that produces $50 \%$ inhibition of paw edema $\left(\mathrm{ED}_{50}\right)$.

The pathogenesis of carrageenan-induced inflammation is linked to the infiltration of immune cells, including macrophages, and their ability to release several proinflammatory cytokines, including TNF- $\alpha$ and IL-6 [23]. The transcription of these proinflammatory cytokines is mediated by the translocation of NF- $\mathrm{KB}$ into the nucleus via the activation of upstream pathways of MAPKs (ERK1/2, JNK, and p38). Additionally, this pathway also mediates the expression of various other mediators, including COX-2 and iNOS, which play crucial roles in the generation of acute inflammation [29]. In regards to the effect of carrageenan-induced paw edema on behavioral changes, pain hypersensitivity was induced after the intraplantar injection of carrageenan [30]. The findings of this study revealed the ability of the curcumin prodrug, CurDG, to reduce the cytokine levels in paw edema tissues compared to the parent drug alone. Hence, this effect could be attributed to the potent inhibition of the aforementioned intracellular signaling cascade, as shown in the in vitro study. Taken together, the results demonstrated the improved anti-inflammatory effect of curcumin against carrageenan-induced paw edema in mice using its ester prodrug CurDG.

\section{Materials and Methods}

\subsection{Materials and Chemicals}

Indomethacin, carrageenan, carboxymethylcellulose, lipopolysaccharide (LPS), 3-(4,5-dimethylthiazol-2-yl)-2,5-diphenyltetrazolium bromide (MTT), and other chemicals were purchased from Sigma Chemical (St. Louis, MO, USA). Curcumin and curcumin diglutaric acid (CurDG) were synthesized as previously described by Muangnoi et al. [10], by the Natural Products for Ageing and Chronic Diseases Research Unit, Faculty of Pharmaceutical Sciences, Chulalongkorn University, Bangkok, Thailand. Briefly, glutaric anhydride in dichloromethane $(9 \mathrm{mmol})$ was added to a solution containing curcumin $(4 \mathrm{mmol})$ and triethylamine $(9 \mathrm{mmol})$ in dichloromethane at $40{ }^{\circ} \mathrm{C}$ with nitrogen. After refluxing for $2 \mathrm{~h}, 0.1 \mathrm{~N} \mathrm{HCl}$ and dichloromethane were added to the reaction mixture. The organic layer was separated, washed with water, dried over anhydrous sodium sulfate, and evaporated until dry using a rotary evaporator. Finally, the residue was purified by crystallization from methanol to yield CurDG as a yellow solid. The chemical structure of CurDG was confirmed by 1H-NMR [10].

\subsection{Cell Culture}

The RAW 264.7 macrophage cell line, purchased from the American Type Culture Collection (ATCC, Rockville, MD, USA), was cultured in Dulbecco's modified Eagle's medium (DMEM) (Invitrogen, Grand Island, NY, USA) supplemented with 10\% fetal bovine serum and 1\% penicillin-streptomycin at $37^{\circ} \mathrm{C}$ in a humidified incubator under $5 \% \mathrm{CO}_{2}$.

\subsection{Evaluation of Cytotoxic Effects of Curcumin and CurDG on Cell Viability of RAW 264.7 Cells}

RAW 264.7 cells $\left(1.5 \times 10^{4}\right.$ cells/well $)$ were seeded in 24 -well plates and incubated for $24 \mathrm{~h}$. After incubation, the medium was removed and $1 \mathrm{~mL}$ of serum-free medium was added per well. Cells were then treated with $0.5 \%$ DMSO or various concentrations of curcumin $(1,5,10,20$, and $50 \mu \mathrm{M})$ and its equimolar concentrations of CurDG. Cell viability was measured using the MTT assay by adding 
MTT solution $(0.5 \mathrm{mg} / \mathrm{mL}$ in PBS), followed by incubation for $4 \mathrm{~h}$. The absorbance was then measured at $540 \mathrm{~nm}$. The results were presented as \% cell viability by comparison with the control group.

\subsection{Anti-Inflammatory Effects of Curcumin and CurDG on LPS-Stimulated RAW 264.7 Cells}

RAW 264.7 cells were seeded in 6-well plates at a density of $1.5 \times 10^{6}$ cells/well for $24 \mathrm{~h}$. Then, cells were washed with phenol red-free medium and the medium was replaced with $2 \mathrm{~mL}$ of phenol red-free medium per well. The cells were then treated with 0.5\% DMSO, curcumin, or CurDG at $5 \mu \mathrm{M}$ (without toxicity) for $1 \mathrm{~h}$, followed by stimulation with $1 \mu \mathrm{g} / \mathrm{mL}$ of LPS [31]. After incubation for $24 \mathrm{~h}$, the culture medium was collected for determination of nitrite, TNF- $\alpha$, and IL-6 levels. The cell pellets were collected for Western blot analysis

\subsubsection{Nitrite Level Measurement (NO Assay)}

The nitrite concentrations in the culture medium as an indicator of nitric oxide levels were analyzed by the Griess reaction by adding $100 \mu \mathrm{L}$ of the culture medium to $50 \mu \mathrm{L}$ of sulfanilamide ( $1 \%$ in $5 \%$ phosphoric acid) in each well of a 96-well plate, followed by incubation for $5 \mathrm{~min}$ in the dark. Then, $50 \mu \mathrm{L}$ of N-1-Napthylenediamine dihydrochloride (NED) solution was added, incubated for $5 \mathrm{~min}$, then the absorbance was measured at $520 \mathrm{~nm}$. The concentration of $\mathrm{NO}$ was determined by comparison to the standard curve of $\mathrm{NaNO}_{2}$ [31].

\subsubsection{Determination of IL-6 and TNF- $\alpha$ Levels}

The levels of IL- 6 and TNF- $\alpha$ were determined with a mouse enzyme-linked immunosorbent assay (ELISA) kit, according to the manufacturer's instructions (BioLegend, San Diego, CA, USA). IL-6 and TNF- $\alpha$ results for each sample were calculated from their respective standard curves.

\subsubsection{Western Blot Analysis}

After treatment (Section 2.4), the cells were washed with ice-cold PBS and lysed by ice-cold RIPA lysis buffer containing a protease and phosphatase inhibitor cocktail (Roche, Mannheim, Germany). Then, centrifugation of the cell lysates at $12,000 \times \mathrm{g}$ and at $4{ }^{\circ} \mathrm{C}$ for $10 \mathrm{~min}$ and the concentration of protein was determined by BCA assay. Equal amounts of each protein sample $(20 \mu \mathrm{g})$ were separated using $10 \%$ sodium dodecyl sulfate-polyacrylamide gel electrophoresis, then the proteins were transferred onto a nitrocellulose membrane. Membranes were blocked with $5 \%$ skim milk for $2 \mathrm{~h}$ and incubated overnight with primary antibodies for iNOS, COX-2, phospho-P38, P38, phospho-ERK, ERK, phosphor-JNK, JNK, (1:1000), or $\beta$-actin $(1: 20,000)$ (Cell Signaling Technology, Danvers, MA, USA) at $4{ }^{\circ} \mathrm{C}$. After $24 \mathrm{~h}$, the membrane was incubated with antirabbit IgG conjugated to HRP secondary antibodies (1:2000) for $90 \mathrm{~min}$. Specific protein bands were exposed to X-ray film and detected using enhanced chemiluminescence (ECL) (Bio-Rad, Hercules, CA, USA). The band densities were quantified using the Image J program and the intensity of the bands was expressed as a relative ratio of the specific proteins and $\beta$-actin or total forms of MAPKs.

\subsection{Animals}

Male ICR mice (18-25 g) were obtained from the Nomura Siam International, Thailand, and maintained at the animal facility of the Faculty of Pharmaceutical Sciences, Chulalongkorn University, Thailand. Animals were housed in a temperature-conditioned room $\left(24 \pm 2{ }^{\circ} \mathrm{C}\right.$ and $40-60 \%$ humidity $)$ with a 12/12 h light/dark cycle. All animals were provided with food and water ad libitum. All the experimental protocols were approved by the Institutional Animal Care and Use Committee of the Faculty of Pharmaceutical Sciences, Chulalongkorn University, Thailand (protocol number: 1833002, 12 March 2018), in agreement with the guidelines of use for laboratory animals for scientific purposes. 


\subsection{Drugs and Treatments}

Mice were randomly divided into 10 groups ( $n=8$ /group) as the vehicle control, indomethacin control, curcumin-treated group (4 doses), and CurDG-treated group (4 doses). Group 1 and 2 served as the vehicle control and indomethacin control, respectively. Groups 3, 4, 5, and 6 received 25, 50, 100 , and $200 \mathrm{mg} / \mathrm{kg}$ of curcumin, respectively; while groups 7, 8, 9, and 10 received CurDG doses equimolar to 25,50,100, and $200 \mathrm{mg} / \mathrm{kg}$ curcumin, respectively. All drugs and treatments were freshly prepared and administered orally at a final volume of $10 \mathrm{~mL} / \mathrm{kg}$. CMC $0.5 \%$ in normal saline was used as the vehicle. Indomethacin was dissolved in CMC (0.5\% in normal saline) and administered at $10 \mathrm{mg} / \mathrm{kg}$. Both curcumin and CurDG were dissolved in 0.5\% CMC. Curcumin at the doses of 25, 50, 100 , and $200 \mathrm{mg} / \mathrm{kg}$; and equimolar doses of CurDG 40.6, 81.1, 162.3, and $324 \mathrm{mg} / \mathrm{kg}$, respectively, were used in this study.

\subsection{Carrageenan-Induced Paw Edema Test}

The anti-inflammatory activity of the compounds was determined using the carrageenan-induced edema test, as described by Winter et al. [32]. Mice were administered with vehicle, indomethacin, or one of four different doses of curcumin or CurDG. After one hour, the mice were injected subcutaneously onto the plantar surface of the left hind paw with $1 \% \lambda$-carrageenan in saline $(50 \mu \mathrm{L} / \mathrm{paw})$. The paw volume was determined at $0 \mathrm{~h}$ (volume of the paw before carrageenan injection, $\mathrm{V}_{0}$ ) and at 1, 2, 3, 4, 5, and $6 \mathrm{~h}$ after carrageenan injection $\left(\mathrm{V}_{\mathrm{t}}\right)$ using a plethysmometer (Model 7150, UGO Basile, Gemonio, VA, Italy). The paw edema was determined as the average increase in the paw volume compared to the control group, calculated according to the following formula [33]:

$$
\% \text { increase of paw volume }=\left(\left(\mathrm{V}_{\mathrm{t}}-\mathrm{V}_{\mathrm{o}}\right) / \mathrm{V}_{\mathrm{o}}\right) \times 100
$$

The anti-inflammatory effects of the compounds were determined as a percentage of inhibition of the paw edema in the treatment groups in comparison to the carrageenan control group [24]:

$$
\% \text { inhibition of paw edema }=\left(\left(V_{t}-V_{o}\right)_{\text {control }}-\left(V_{t}-V_{o}\right)_{\text {treatment }}\right) /\left(V_{t}-V_{o}\right)_{\text {control }} \times 100
$$

\subsection{Determination of Proinflammatory Cytokines in Inflamed Paw Tissues}

Upon completion of the paw edema measurements, hind paws injected with carrageenan were collected. The hind paws were dissected at the level of the calcaneus bone and the soft tissue samples were removed and stored at $-80{ }^{\circ} \mathrm{C}$ until use. The tissue samples were weighed and paw tissues $(20 \%(w / v))$ were homogenized in ice-cold PBS at pH 7.4. Then, the homogenates were centrifuged at $10,000 \mathrm{rpm}$ for $10 \mathrm{~min}$ at $4{ }^{\circ} \mathrm{C}$ and the supernatants were collected. Three to five samples of supernatants were randomly picked to determine the concentrations of TNF- $\alpha$ and IL- 6 and IL1- $\beta$ using ELISA kits (BioLegend, San Diego, CA, USA), according to the manufacturer' protocol.

\subsection{Statistical Analysis}

Results are presented as the mean \pm SD values $(n=3)$ of three independent experiments for in vitro studies and as the mean \pm SEM values $(n=8)$ for the in vivo studies. The statistical differences between groups were analyzed by one-way analysis of variance (ANOVA) followed by Fisher's LSD post hoc test. Here, $p$-values $<0.05$ were considered statistically significant. All statistical calculations were performed using Graph Pad Prism 7.0 (USA) statistical software.

\section{Conclusions}

In summary, the present study provides evidence that CurDG has a more potent anti-inflammatory effect than curcumin both in vitro and in vivo through suppression of inflammatory mediator production (IL-6, TNF- $\alpha$, COX-2, and iNOS). The molecular mechanisms by which CurDG demonstrated its effects involve the modulation of the phosphorylation of MAPK signaling pathways, such as ERK1/2, 
JNK, and p38. The results provide the first experimental evidence for CurDG as a promising therapeutic agent for treating disorders characterized by inflammation.

Author Contributions: Conceptualization, R.P. and P.T.; methodology, R.P. and C.M.; validation, R.P. and C.M., formal analysis, R.P., C.M., and P.W.D.W.; investigation, R.P.; resources, P.T. and P.R.; data curation, R.P.; writing —original draft preparation, R.P., P.W.D.W., C.M., and H.; writing-review and editing, P.W.D.W. and O.V.; visualization, H.; supervision, P.T.; project administration, P.T.; funding acquisition, P.T. and P.R. All authors have read and agreed to the published version of the manuscript.

Funding: This research was funded by the 90th Anniversary of Chulalongkorn University Fund, Ratchadaphiseksomphot Endowment Fund (Grant number: GCUGR1125621017M). and the Ratchadaphiseksomphot Endowment Fund of Chulalongkorn University (Grant number: CU-GR_60_24_33_07, P. Towiwat).

Acknowledgments: The authors thank Timothy Maher, School of Pharmacy, MCPHS University, USA, for editorial assistance.

Conflicts of Interest: The authors declare no conflict of interest.

\section{Abbreviations}

$\begin{array}{ll}\text { CurDG } & \text { Curcumin diglutaric acid } \\ \text { NF-kB } & \text { Nuclear factor kappa B } \\ \text { MAPKs } & \text { Mitogen-activated protein kinases } \\ \text { JNKs } & \text { c-Jun N-terminal kinases } \\ \text { ERK1/2 } & \text { Extracellular signal-regulated kinases } \\ \text { IL-1 } \beta & \text { Interleukin-1beta } \\ \text { IL-6 } & \text { Interleukin-6 } \\ \text { TNF- } \alpha & \text { Tumor necrosis factor } \\ \text { NO } & \text { Nitric oxide } \\ \text { PGE2 } & \text { Prostaglandine2 } \\ \text { iNOS } & \text { Inducible nitric oxide synthase } \\ \text { COX-2 } & \text { Cyclooxygenase-2 } \\ \text { NSAIDs } & \text { Non-steroidal anti-inflammatory drugs } \\ \text { AUC } & \text { Area under the curve } \\ \text { TLR-4 } & \text { Toll-like receptors } \\ \text { LPS } & \text { Lipopolysaccharide } \\ \text { MTT } & \text { 3-(4,5-Dimethylthiazol-2-yl)-2,5-diphenyltetrazolium bromide } \\ \text { DMSO } & \text { Dimethyl sulfoxide } \\ \text { NED } & \text { N-1-Napthylenediamine dihydrochloride } \\ \text { ELISA } & \text { Enzyme-linked immunosorbent assay } \\ \text { ECL } & \text { Enhanced chemiluminescence } \\ \text { SEM } & \text { Standard error of the mean } \\ \text { CMC } & \text { Carboxymethyl cellulose } \\ & \\ \end{array}$

\section{References}

1. Batista, D.C.; Silva, D.P.B.; Florentino, I.F.; Cardoso, C.S.; Gonçalves, M.P.; Valadares, M.C.; Lião, L.M.; Sanz, G.; Vaz, B.G.; Costa, E.A.; et al. Anti-inflammatory effect of a new piperazine derivative: (4-methylpiperazin-1-yl)(1-phenyl-1H-pyrazol-4-yl)methanone. Inflammopharmacology 2017, 26, 217-226. [CrossRef] [PubMed]

2. Lee, S.; Park, B.-R.; Moon, S.-M.; Han, S.H.; Kim, C.S. Anti-inflammatory potential of Trifolium pratense L. leaf extract in LPS-stimulated RAW264.7 cells and in a rat model of carrageenan-induced inflammation. Arch. Physiol. Biochem. 2018, 126, 74-81. [CrossRef] [PubMed]

3. Jeong, Y.H.; Oh, Y.-C.; Cho, W.-K.; Lee, B.; Ma, J.Y. Anti-inflammatory effects of melandrii herba ethanol extract via inhibition of NF- $\mathrm{kB}$ and MAPK signaling pathways and induction of HO-1 in RAW 264.7 cells and mouse primary macrophages. Molecules 2016, 21, 818. [CrossRef] [PubMed]

4. Buadonpri, W.; Wichitnithad, W.; Rojsitthisak, P.; Towiwat, P. Synthetic curcumin inhibits carrageenan-induced paw edema in rats. J. Heal. Res. 2009, 23, 11-16. 
5. Chan, M.M.-Y.; Huang, H.-I.; Fenton, M.R.; Fong, D. In vivo inhibition of nitric oxide synthase gene expression by curcumin, a cancer preventive natural product with anti-inflammatory properties. Biochem. Pharmacol. 1998, 55, 1955-1962. [CrossRef]

6. Jurenka, J.S. Anti-inflammatory properties of curcumin, a major constituent of Curcuma longa: A review of preclinical and clinical research. Altern. Med. Rev. J. Clin. Ther. 2009, 14, 141-153.

7. Bulboacă, A.; Boarescu, P.M.; Bolboacă, S.; Blidaru, M.; Feștilă, D.; Dogaru, G.; Nicula, C. Comparative effect of curcumin versus liposomal curcumin on systemic pro-inflammatory cytokines profile, Mcp-1 and RANTES in experimental diabetes mellitus. Int. J. Nanomed. 2019, 14, 8961-8972. [CrossRef]

8. Boarescu, P.M.; Boarescu, I.; Bocsan, C.I.; Pop, R.M.; Gheban, D.; Bulboacă, A.E.; Nicula, C.A.; Rajnoveanu, R.-M.; Bolboacă, S.D. Curcumin nanoparticles protect against isoproterenol induced myocardial infarction by alleviating myocardial tissue oxidative stress, electrocardiogram, and biological changes. Molecules 2019, 24, 2802. [CrossRef] [PubMed]

9. Bulboacă, A.E.; Bolboacă, S.; Bulboacă, A.C.; Porfire, A.S.; Tefas, L.R.; Suciu, S.M.; Dogaru, G.; Stănescu, I.C. Liposomal curcumin enhances the effect of naproxen in a rat model of migraine. Med. Sci. Monit. 2019, 25, 5087-5097. [CrossRef]

10. Muangnoi, C.; Jithavech, P.; Na Bhuket, P.R.; Supasena, W.; Wichitnithad, W.; Towiwat, P.; Niwattisaiwong, N.; Haworth, I.S.; Rojsitthisak, P. A curcumin-diglutaric acid conjugated prodrug with improved water solubility and antinociceptive properties compared to curcumin. Biosci. Biotechnol. Biochem. 2018, 82, 1301-1308. [CrossRef]

11. Rautio, J.; Kumpulainen, H.; Heimbach, T.; Oliyai, R.; Oh, D.; Järvinen, T.; Savolainen, J. Prodrugs: Design and clinical applications. Nat. Rev. Drug Discov. 2008, 7, 255-270. [CrossRef] [PubMed]

12. Qandil, A.M. Prodrugs of nonsteroidal anti-inflammatory drugs (NSAIDs), more than meets the eye: A critical review. Int. J. Mol. Sci. 2012, 13, 17244-17274. [CrossRef] [PubMed]

13. Fürst, R.; Zündorf, I. Plant-derived anti-inflammatory compounds: Hopes and disappointments regarding the translation of preclinical knowledge into clinical progress. Mediat. Inflamm. 2014, 2014, 1-9. [CrossRef] [PubMed]

14. Maione, F.; Russo, R.; Khan, H.; Mascolo, N. Medicinal plants with anti-inflammatory activities. Nat. Prod. Res. 2015, 30, 1343-1352. [CrossRef]

15. Larrosa, M.; Tomé-Carneiro, J.; Yáñez-Gascón, M.J.; Alcántara, D.; Selma, M.V.; Beltrán, D.; Garcia-Conesa, M.T.; Urbán, C.; Lucas, R.; Tomás-Barberán, F.A.; et al. Preventive oral treatment with resveratrol pro-prodrugs drastically reduce colon inflammation in rodents. J. Med. Chem. 2010, 53, 7365-7376. [CrossRef]

16. Kim, M.K.; Park, K.-S.; Yeo, W.-S.; Choo, H.; Chong, Y. In vitro solubility, stability and permeability of novel quercetin-amino acid conjugates. Bioorganic Med. Chem. 2009, 17, 1164-1171. [CrossRef]

17. Cao, F.; Guo, J.-X.; Ping, Q.; Liao, Z.-G. Prodrugs of scutellarin: Ethyl, benzyl and N,N-diethylglycolamide ester synthesis, physicochemical properties, intestinal metabolism and oral bioavailability in the rats. Eur. J. Pharm. Sci. 2006, 29, 385-393. [CrossRef]

18. Bangphumi, K.; Kittiviriyakul, C.; Towiwat, P.; Rojsitthisak, P.; Khemawoot, P. Pharmacokinetics of curcumin diethyl disuccinate, a prodrug of curcumin, in wistar rats. Eur. J. Drug Metab. Pharmacokinet. 2015, 41, 777-785. [CrossRef]

19. Choi, Y.H.; Kim, G.-Y.; Lee, H.H. Anti-inflammatory effects of cordycepin in lipopolysaccharide-stimulated RAW 264.7 macrophages through Toll-like receptor 4-mediated suppression of mitogen-activated protein kinases and NF-kB signaling pathways. Drug Des. Dev. Ther. 2014, 8, 1941-1953. [CrossRef]

20. Vendramini-Costa, D.B.; Spindola, H.M.; De Mello, G.C.; Antunes, E.; Pilli, R.A.; Carvalho, J. Anti-inflammatory and antinociceptive effects of racemic goniothalamin, a styryl lactone. Life Sci. 2015, 139, 83-90. [CrossRef]

21. Reis, E.F.; Castro, S.; Alves, C.C.S.; Oliveira, E.E.; Corrêa, T.A.; Almeida, M.V.; Ferreira, A.P. Lipophilic amino alcohols reduces carrageenan-induced paw edema and anti-OVA DTH in BALB/c mice. Int. Immunopharmacol. 2013, 17, 727-732. [CrossRef] [PubMed]

22. Lee, S.-H.; Kwak, C.-H.; Lee, S.-K.; Ha, S.-H.; Park, J.; Chung, T.-W.; Ha, K.-T.; Suh, S.-J.; Chang, Y.-C.; Chang, H.W.; et al. Anti-inflammatory effect of ascochlorin in lps-stimulated RAW 264.7 macrophage cells is accompanied with the down-regulation of iNOS, COX-2 and proinflammatory cytokines through NF- $\mathrm{kB}$, ERK1/2, and p38 signaling pathway. J. Cell. Biochem. 2016, 117, 978-987. [CrossRef] [PubMed] 
23. Bajpai, V.K.; Alam, B.; Quan, K.T.; Ju, M.-K.; Majumder, R.; Shukla, S.; Huh, Y.S.; Na, M.; Lee, S.H.; Han, Y.-K. Attenuation of inflammatory responses by (+)-syringaresinol via MAP-Kinase-mediated suppression of NF-kB signaling in vitro and in vivo. Sci. Rep. 2018, 8, 9216. [CrossRef] [PubMed]

24. Moon, S.-M.; Lee, S.A.; Hong, J.H.; Kim, J.-S.; Kim, D.K.; Kim, C.S. Oleamide suppresses inflammatory responses in LPS-induced RAW264.7 murine macrophages and alleviates paw edema in a carrageenan-induced inflammatory rat model. Int. Immunopharmacol. 2018, 56, 179-185. [CrossRef] [PubMed]

25. Lee, S.; Moon, S.-M.; Choi, Y.H.; Han, S.H.; Park, B.-R.; Choi, M.S.; Kim, J.-S.; Kim, Y.H.; Kim, D.K.; Kim, C.S. Aqueous extract of Codium fragile suppressed inflammatory responses in lipopolysaccharide-stimulated RAW264.7 cells and carrageenan-induced rats. Biomed. Pharmacother. 2017, 93, 1055-1064. [CrossRef] [PubMed]

26. Makni, S.; Tounsi, S.; Rezgui, F.; Trigui, M.; Bouassida, K.Z. Emex spinosa (L.) Campd. ethyl acetate fractions effects on inflammation and oxidative stress markers in carrageenan induced paw oedema in mice. J. Ethnopharmacol. 2019, 234, 216-224. [CrossRef]

27. Srimal, R.C.; Dhawan, B.N. Pharmacology of diferuloyl methane (curcumin), a non-steroidal anti-inflammatory agent*. J. Pharm. Pharmacol. 1973, 25, 447-452. [CrossRef]

28. Panda, S.S.; Girgis, A.S.; Thomas, S.J.; Capito, J.E.; George, R.F.; Salman, A.; El-Manawaty, M.A.; Samir, A. Synthesis, pharmacological profile and 2D-QSAR studies of curcumin-amino acid conjugates as potential drug candidates. Eur. J. Med. Chem. 2020, 196, 112293. [CrossRef]

29. Li, Y.-Y.; Huang, S.-S.; Lee, M.-M.; Deng, J.-S.; Huang, G.-J. Anti-inflammatory activities of cardamonin from Alpinia katsumadai through heme oxygenase-1 induction and inhibition of NF- $\mathrm{kB}$ and MAPK signaling pathway in the carrageenan-induced paw edema. Int. Immunopharmacol. 2015, 25, 332-339. [CrossRef]

30. Deuis, J.R.; Vetter, I. The thermal probe test: A novel behavioral assay to quantify thermal paw withdrawal thresholds in mice. Temperature 2016, 3, 199-207. [CrossRef]

31. Sorasitthiyanukarn, F.N.; Muangnoi, C.; Thaweesest, W.; Rojsitthisak, P.; Rojsitthisak, P. Enhanced cytotoxic, antioxidant and anti-inflammatory activities of curcumin diethyl disuccinate using chitosan-tripolyphosphate nanoparticles. J. Drug Deliv. Sci. Technol. 2019, 53, 101118. [CrossRef]

32. Winter, C.A.; Risley, E.A.; Nuss, G.W. Carrageenin-induced edema in hind paw of the rat as an assay for antiinflammatory drugs. Exp. Boil. Med. 1962, 111, 544-547. [CrossRef] [PubMed]

33. Ma, Y.; Li, Y.; Li, X.; Wu, Y. Anti-inflammatory effects of 4-methylcyclopentadecanone on edema models in mice. Int. J. Mol. Sci. 2013, 14, 23980-23992. [CrossRef] [PubMed] 